instrument for the study of cerebral diseases, and who do not care to obtain their knowledge of it from a general treatise on ophthalmology. 'The English version of 'Zander' has been for some time out of print, and Mr. Wilson's is the only monograph in the language on this subject that can claim to be at once accurate and tolerably complete.

Dr. Galezowski is a man of much vigour of mind, much originality of conception, and much industry; but his industry does not always lead him to verify the statements that he makes. In the volume before us he has made a valuable suggestion in his idea that colour vision should be carefully studied as an element in diagnosis. This, which is the sole merit of the work, is contained, of course, in the title; and in the letterpress the author falls into the amazing blunder of propounding a physical theory of colour vision, based on a belief about the position of the retinal cones that is the actual reverse of the truth. His theory in no way affects the clinical value of his statement, that certain diseases influence colour vision in a characteristic manner; but it is quite evident that this statement is a hasty one, resting at present on no satisfactory evidence. The question is well worthy of full and careful examination, and Dr. Galezowski merits the thanks of the profession for having directed attention to its importance.

The 'Transactions of the American Ophthalmological Society' is but a small volume, but it contains many excellent contributions, and affords gratifying proof of the earnest work of our transatlantic brethren. We would remark, as especially worthy of commendation, the papers by Dr. John Green upon improved test-types, and upon improved methotls of determining the kind and degree of astigmatism. These papers are illustrated by diagrams of test objects, such that surgeons in ophthalmic practice will find it useful to become possessed of the book.

\title{
Review IX.
}

1. Theoretical and Practical Midwifery. By P. Cazeaux. Revised and annotated by S. TARnier. Fifth American from the seventh French edition, by WM. R. Bullock, M.I. Pp. 1124.

2. Puerperal Uramic Eclampsia. By Arthur Scott Donkin, M.D., Lecturer on Medical Jurisprudence, \&c., to the University of Durham. P. 8.

3. A Handbook on Uterine Therapeutics, and on Diseases of Women. By EDward JoHN TILT, M.D. M.R.C.P., \&c. Third edition. Pp. 423. 
4. Uterine Catarrh frequently the cause of Sterility; new treatment. By H. E. Gantillon, M.D. Pp. 88.

5. On Uterine Hydatidiform Disease, or Cystic Degeneration of the Ovum. By Thomas More Madpen, M.R.I.A. Pp. 18.

6. On the Diagnosis and Treatment of Uterine Polypi. By Grorge H. KidD, M.D., F.R.C.S.I. Pp. 32.

7. Beitrage zur Casuistite der Uterus Fibroide. Inaugural-I)issertation, vorgelegt von August Hausmann. Pp. 51 .

Contributions to the Study of the Fibroid Uterus. By A. Hausmann.

AFTER ten years' interval we again bring to notice the most complete treatise of the day on midwifery. The seventh edition of Cazeaux, revised and annotated by M. S. Tarnier, is the fifth translated edition of Dr. Bullock. The work is, of course, well known to writers on obstetrics, but we think it ought to be placed in every hospital library within the reach of the student.

M. Tarnier has fairly accomplished his task of bringing the original work up to the present time, and without altering the felicitous style of Cazeaux he has, by retouching the text where necessary, given a new direction and meaning to the original
ideas.

Some alteration has been made in the plan of the old edition, and M. Tarnier has availed himself of recent researches as to the structure of the uterus and ovary. Thus he refers to M. Rouget's memoir, and describes the erectile tissue of the uterus, the muscular layers in the broad ligament, and in the stroma of the ovary. Following M. Sappey he tells us that-

"The ovary is composed of a central portion and of a superficial, resicles. These M. Sappey calculates are over 300,000 in each ovary, making near 700,000 for the individual. If, therefore, all the ova existing in the surface of the ovaries of a young woman were to be fecundated and undergo all their phases of development, it would require but two women to furnish inhabitants for a capital like Paris, containing $1,600,000$ souls ...... There are as many ovisacs in the foetus as there will be at puberty."

In the description of the chorion, M. Robin's essay in 'Le Journai de Physiologie,' 1861, is largely made use of ; and his views regarding the placenta are also given in detail. the foetus in uterô-the oldest, viz. that of gravitation, has been lately reasserted with additional evidence by Dr. Duncan. ${ }^{1}$ M. Dubois' theory is that-

1 'Researches in Obstetrics.' 
"The vertex presentation is a consequence of the instinctive will of the fœtus itself; and Cazeaux suggests that, as the uterus being developed during the first six months at the expense of its fundus is spread out superiorly, but, on the contrary, is much contracted below, it is evident that the pelvic extremity which from the folded condition of the lower limbs is much more voluminous than the head, must naturally lie in the largest cavity, that is, towards the fundus, and consequently that the cranium will descend to the cervix. There can be no doubt that the inferior part spreads out in the last three months nearly as much as the fundus, but then the fœtal vertical diameter is too long to permit it to traverse the transverse diameter of the uterus, and hence, with some few exceptions, the child is forcibly retained in the position it first assumed."

M. Tarnier has added to the chapters on the mechanism of labour a brief review of M. Pajot's teaching on the subject.

"The head and body of the fotus form two masses, the long diameters of which have opposite directions, from before backwards for the head, and transverse for the body. These two diameters are at right angles to each other; whence it happens that when one of the two parts has a direction adapted to its ready exit from the pelvis the other will have an opposite direction.

"We have thus to describe six stages in the delivery:

$\left.\begin{array}{l}\left.\text { "1st stage } \quad \text {. } \begin{array}{l}\text { Compression } \\ \text { 2nd " } \\ \text { 3rd } " \text { Engagement } \\ \text { 4th } " \text { Rotation } \\ \text { 5th } " \text { Disengagement } \\ \text { 6th } " \text {. Rotation }\end{array}\right\} \text { of the first fœtal part. } \\ \text { Expulsion }\end{array}\right\}$ of the second fœtal part."

In the treatment of the secundines, the directions are to draw gently on the cord, and wait for an hour or so after the child has passed before taking them away; and no allusion is made to the method much advocated at present in England of taking away the secundines a few minutes after the child, waiting only long enough for the uterus to rest and again contract, and, if needful, introducing the hand while all the soft parts are relaxed. A chapter is added by M. Tarnier on hydatids of the uterus chiefly drawn from Dr. Cayla's thesis. The effect on the fotus depends on the amount of disease in the chorion. Should all the villi become dropsical, the death of the fotus would necessarily ensue, and occurring at a period very near that of conception, it might undergo solution in the amniotic fluid and thus disappear. Should the alteration be more recent or less complete, we should have an embryonic mole in which the body of the foetus would present various grades of development. Most writers who have noticed the subject hold similar 
views as to the pathology of this condition of the ovum. Dr. Farre ${ }^{1}$ says-

"It is almost needless to observe that the presence of a true chorion structure, which these substances invariably exhibit even in their most degenerated and abnormal forms, constitutes unquestionable evidence of a prior act of impregnation."

Dr. More Madden supports by facts and argument an opposite opinion.

"The numerous theories," says he, "by which the formation of inter-uterine hydatidiform masses have been accounted for, may all be included in one or other of the following hypotheses:-The first and most recent of which is, that hydatid moles are necessarily connected with impregnation, and are the result of embryonic death and morbid growth of some portion of the ovum. The second is, that hydatid moles are not connected with pregnancy at all, but are simply the result of diseased ovarian action. The last, and perhaps the oldest of the theories referred to, is, that these vesicular uterine masses are similar in their structure and development to the true hydatids found in other parts of the body. . . . . The first of these theories is, I think, clearly disproved (as a universal law) by the numerous cases on record in which uterine hydatids were expelled by unmarried women whose chastity was unimpeachable. I therefore think it by no means improbable that some of these instances might be accounted for on the supposition that a morbid action or monstrous growth may occur in one of the Graaffian vesicles which modern physiology has shown are discharged from the ovaries at each menstrual period, and that this hydatidiform disease of the unimpregnated ovum may be in some way connected with ovarian disease."

Dr. Madden refers to five cases, two related by Dr. Ashwell, in one of which the patient was a widow of two years, and of undoubted reputation; in another, a maiden lady, where the hymen was unruptured, and of whose chastity there could not be a suspicion; two cited by Dr. Ashley, one of which was under his own care, and symptoms of hydatid formation appeared a few weeks after delivery, and under circumstances which precluded the possibility of a subsequent impregnation, the other related by Dr. Knoch, of Heilgenbeil ; and a case related by Dr. Hamilton, where the lady had been living apart from her husband for two years, and he was satisfied as to her chastity.

On the point of treatment, when the diagnosis is established, Dr. Madden differs from M. Pajot, the present Professor of Obstetrics at the Clinique in Paris. In a case where the patient supposed herself pregnant three months the professor advised

1 'Cyc. Anat. and Phys.,' vol. v, p. 698. 
" the insertion of a gum elastic catheter through the os internum, and the administration of ergot."

Dr. Madden says - "As cases have occurred where hydatids coexisted with natural pregnancy, interference may run the grave risk of destroying a living foetus."

With respect to the alimentation of women directly after confinement, M. Le Groux, of the Hotel Dieu, is quoted as adopting the views now pretty general here, and especially insisted on by Dr. Graily Hewitt, in giving meat and soup.

In the chapter on abortion, repeated small venesections are recommended as a prophylactic, where the patient is plethoric, and powdered savine when she is anæmic.

In contraction of the pelvis, M. Tarnier gives $2 \frac{5}{8}$ inches as the least diameter compatible with safe delivery. Churchill states that a living child cannot pass through a pelvis whose small diameter is less than three inches.

In unavoidable hæmorrhage M. Tarnier would plug, and wait; and, secondly, if necessary, rupture the membranes.

Dr. Barnes's views as to the development of the placenta and its zonic attachments, on which he founds his treatment of unavoidable hæmorrhage, are not alluded to, though $\mathbf{M}$. Tarnier seems well acquainted with his uterine dilator, which instrument M. Tarnier uses in conjunction with one of his own invention where premature labour is to be induced.

M. Tarnier's instrument consists of a gum elastic catheter, the upper end of which being made with thin walls, dilates into a ball when filled with water or air. This he passes with a guide into the uterus. The ball prevents its expulsion, and the ovular membranes remain unbroken. As soon as the cervix admits, M. Tarnier introduces Barnes's dilator. The other obstetric operations, as the use of the forceps, vectis, cephalotribe, with M. Pajot's method of 'repeated cephalotripsy without traction,' Cæsarian section, \&c., are fully described.

M. Tarnier has most ably put the finishing touches to Cazeaux's description of allbuminuria during pregnancy, and its connection with eclampsia; he sums up the causes of albuminuria as arising from either-1. Super-albuminosis of the blood, for though the albumen is diminished relatively to the mass of the other constituents, there is a marked predominance of albumen as compared with the corpuscles (Gubler); or-2. Over distension of the renal vessels; or-3. Albuminous nephritis, which may be either primary or secondary.

Three cases are published by Dr. Donkin, who draws from clinical considerations the same conclusion as to treatment that Cazeaux, and, in fact, nearly all obstetricians do, that a large 
bleeding from an open vein is the first measure to be adopted. We shall conclude our notice by quoting Cazeaux's opinion on the use of chloroform: "We," says he, "formerly proscribed its use in the majority of cases, but facts published by our colleagues, as well as the result of personal observation, have greatly changed our first opinion; so that we are now convinced that when eclampsia comes on, during either pregnancy or labour, the use of chloroform may be of some service. At other times it is in France confined almost exclusively to cases of difficult parturition."

Dr. Tilt wishes his book " to be taken as a protest against the disparagement of a considerable amount of therapeutical wisdom that has been handed down to us for our guidance in the treatment of disease from one generation of medical observers to another."

Therapeutical writing is not synonymous with therapeutical wisdom. Assertions that this or that drug is good for this or that disease are as unserviceable as are proverbs for guidance in particular actions, while the most fatal errors in practice have been committed under shelter of authority. The loss of faith in therapeutics is simply consequent on the discovery that the traditions are not based on fact. Specialism too often trammels the observer. Dr. Tilt (p. 337) says: "A patient of mine has had her back broken, in the literal sense of the word, by internal metritis, for the upper dorsal vertebræ formed a right angle with the lower and lumbar vertebræ." Dr. Tilt apparently attributes caries of the vertebræ, and consequent angular curvature, "to the patient remaining in a crouching position for three weeks on account of a severe attack of endometritis. Eighteen months after the metritis," for which the patient was "diligently treated," but no reference made to the spinal disease, "her mother noticed the projection of the vertebræ."

In writing on a given subject care should be taken to warn the reader when danger may be incurred in the use of certain modes of treatment. Dr. Tilt classes bromine with tincture of iodine and nitrate of silver as a topical application, and calls it a powerful detergent, but says not a word as to its violent caustic powers, which are far more unmanageable than potassa fusa. Perforation of the recto-vaginal septum, we are well informed, has taken place, though the application to the cervix was made by skilled hands. Amputation of the uterus in cases of old procidentia can hardly be deemed an easy operation, or the danger slight. We are very incredulous, too, as to the efficacy of applying a white-hot iron to the ear as a cure for sciatica, though Professor Malgaigne is said to have ascertained it; nor is Récamier's prescription for the cure of hysteric con- 
vulsions likely to be much used-that of causing the lady's maid to sit on her mistress's belly.

The use of large doses of digitalis in menorrhagia, once tried by Dr. Robert Lee and Dr. Dickenson, at St. George's Hospital, has not found much favour since that time; and Dr. Tilt should have cautioned his readers against the occurrence of unexpected poisoning. But while we thus protest against certain blemishes, we can praise Dr. 'Tilt's book as containing many useful hints as to conduct in the consulting-room, and also at the bedside. The junior will gladly avail himself of instruction offered by a well-experienced practitioner, and find much information as to the use of douches, topical applications, the substitution of alkaloids for extracts, and of glycerine and starch as a vehicle in place of the disgusting fatty preparations which often make the remedy more distressful than the disease.

The diagnosis and treatment of uterine polypi are now well settled. Still from time to time men of observation make or suggest improvements in particulars, or cautions as to the mode of carrying out principles generally agreed to. Dr. Hausmann, in his thesis for the Doctorat at Jena, tells us the opinions held on the subject in that medical school; but as they present nothing new to those who have access to the many English writers-Graily Hewitt, West, Churchill, M‘Clintock, Hutchinson, and many others-we may pass it over, merely noting that Dr. Hausmann gives the details of four cases of fibroï. In one the ligature, now nearly discarded in England, except, we are informed, in the Hospital for Women at Soho-square; in two others, scissors; and, in the fourth, a ligature was applied for a few hours, and then the mass was removed with the knife.

Dr. Kidd divides uterine polypi into fibrous and mucous, the latter being subdivided by a cystic or glandular variety. As his object is merely to relate his own experience, he does not go into pathological or histological details of other varieties; and the points worthy of notice in his essay relate to treatment.

Four cases of ordinary fibroïd are detailed. Dr. Kidd prefers the tangle tent to the sponge, but the chief objection to the latter-its offensiveness-has been removed by preparing it with carbolic acid ${ }^{1}$ and cacao butter. On the suggestion of Dr. Ringland, Dr. Kidd, in sundry cases of uterine polypi, applied strong nitric acid to the uterine cavity, and approves of the application. He seems to have no fear either of this bold treatment, or of mopping out the uterus with a saturated solu-

1 “Carbolised Sponge Tents." Robert Ellis, Esq., 'Obstetrical Transactions,' vol. ix, 1868. 
tion of perchloride of iron in glycerine. In treating cases of mucous polypi, Dr. Kidd found, as Marion Sims pointed out, that the pressure of the tent was often sufficient to remove the growth; so that on exploration no tumour was perceptible, and there was no recurrence of the former symptoms.

Dr. Gantillon's brochure, somewhat pretentiously put forth, is suggestive of puff:

"Uterine catarrh," says he, "is one of the principal causes of sterility, because when young women are affected with it all the tissues are in a flaccid state, and do not sufficiently oppose the passage of liquids contained in the vagina; and if some spermatozoons should penetrate the cavity of the cervix the liquid in which they are carried would soon flow back again, for the orifices, instead of being closed, remain wide open in almost every case of uterine engorgement. Besides this unfavorable mechanical condition, the reaction of the uterine upon the spermatic liquids (in leucorrhœa) is one of the principal causes of the sterility of young women."

Dr. Gantillon's new (?) treatment is to inject, with a graduated syringe and a tube of small diameter, a solution of nitrate of silver. We need simply remark that the treatment is no novelty, but many practitioners are in the habit of using a uterine porte caustique, both in cases of catarrh and in metrorrhagia.

\section{Review X.}

On Pyamia, or Suppurative Fever. Being the Astley Cooper Prize Essay for 1868. By Peter Murray Brainwoon, M.D., L.R.C.S.E., late President of the Royal Medical Society of Edinburgh. London. Pp. 287.

In modern times, when rapid change is the most prominent feature of the age, to a generation which has seen a complete revolution in medical practice, anything definitely and absolutely settled would be a relief, and perhaps a novelty. We live in that painful and unpleasant interregnum which lies between the reign of ignorance, even when concealed under the garb of unusual knowledge, and the more perfect science of modern times, whereby, with absolute certainty, the future may be foretold from our knowledge of the past. The science which strikes us all as the most perfect embodiment of human knowledge is astronomy, 